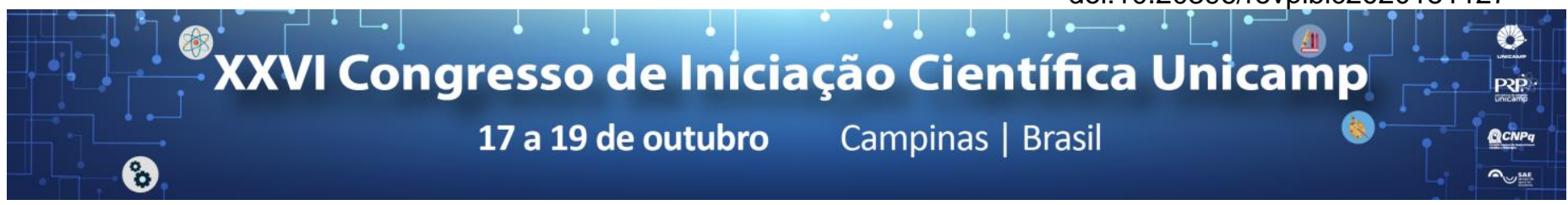

\title{
Desenvolvimento de um método para identificar emissor alfa em um material desconhecido.
}

\section{Pedro B. P. Gomes, Julio Cesar Hadler Neto e Arnaldo Luis Lixandrão Filho}

\section{Resumo}

Neste projeto foi estabelecido um método para a identificação de fontes de partícula alfa utilizando detectores de traços, Poly Allyl Diglycol Carbonate (PADC), comercialmente chamado de CR-39. A partir das imagens obtidas nos detectores originadas de filme fino de Am-241, filme fino de Urânio natural e de filme infinito de Urânio natural foi possível determinar que a amostra de emissor alfa de energia desconhecida era, de fato, compatível com o que se obteve para a amostra de filme infinito de urânio.

\section{Palavras-chave:}

Cr-39, Partículas alfa, Fonte Radioativa.

\section{Introdução}

Radônio (e filhos) constituem o contaminante radioativo que mais afeta a saúde do ser humano. A separação radônio e filhos (Po-214 e Po-218) com detectores de traço de partículas alfa constituiria um avanço para o melhor entendimento desta contaminação. Por esse motivo buscamos desenvolver um método capaz de distinguir diferentes fontes de partículas alfa através de seu espectro energético.

Este método utiliza a análise das características dos traços observados ao microscópio ótico (nível de cinza e área) de modo a comparar, via testes estatísticos diferentes fontes radioativas.

\section{Resultados e Discussão}

Uma lâmina de CR-39 de tamanho adequado foi irradiada separadamente com os quatro emissores alfa aqui empregados, a saber, filme fino de Am-241(AmFF), filme fino (UFF) e infinito ( $U_{F I}$ ) de Urânio natural e a amostra desconhecida (AD) conforme diagrama na Figura $1 \mathrm{~A}$ ). Após a irradiação o CR-39 é submetido a um ataque químico com $\mathrm{NaOH} 6,25$ molar por 400 minutos à $70^{\circ} \mathrm{C}$. Em seguida foram feitas imagens com o microscópio óptico mapeando os traços de todo o detector para que se tenha a maior quantidade de dados possíveis.

Para análise de imagens consideramos inicialmente a área dos traços uma vez que um corte no nível de cinza removeria os traços menos energéticos muito frequentes em amostras com geometria de filme infinito. Na Figura 1 B) estes traços estão marcados com diferentes cores. No gráfico da Figura $1 \mathrm{C}$ ), todos os traços com área mínima de 1000 pixels ao quadrado, e excentricidade ( razão entre o diâmetro maior e o diâmetro menor) menor do que 1,1, e independente do nível de cinza, são analisados. A restrição quando a excentricidade foi necessária para garantir uma homogeneidade mínima no nível de cinza dos traços.

Com essa metodologia obtivemos os histogramas da Figura $1 \mathrm{C}$ ), onde estão descritas, por exemplo, as curvas para uma amostra de filme fino de Am-241(vermelho) e filme infinito de Urânio natural (azul). A distribuição dos traços originados do Am-241 tem a característica de uma fonte de filme infinito pois se observa uma distribuição aproximadamente gaussiana bem definida. Por outro lado a distribuição vinda de filme infinito ela não apresenta um pico do tipo gaussiano havendo uma distribuição de traços num espectro bastante largo, característica da perda de energia dos traços dentro da própria amostra.
Para comparar as distribuições utilizamos dois testes estatísticos, o $\chi^{2}$ e o Kolmogorov-Smirnov que tiveram sucesso em classificar que a amostra desconhecida desde experimento era compatível com a amostra de filme infinito de urânio natural.

Figura 1. A) Metodologia, B) Traços no Cr-39, C) histogramas das amostras.

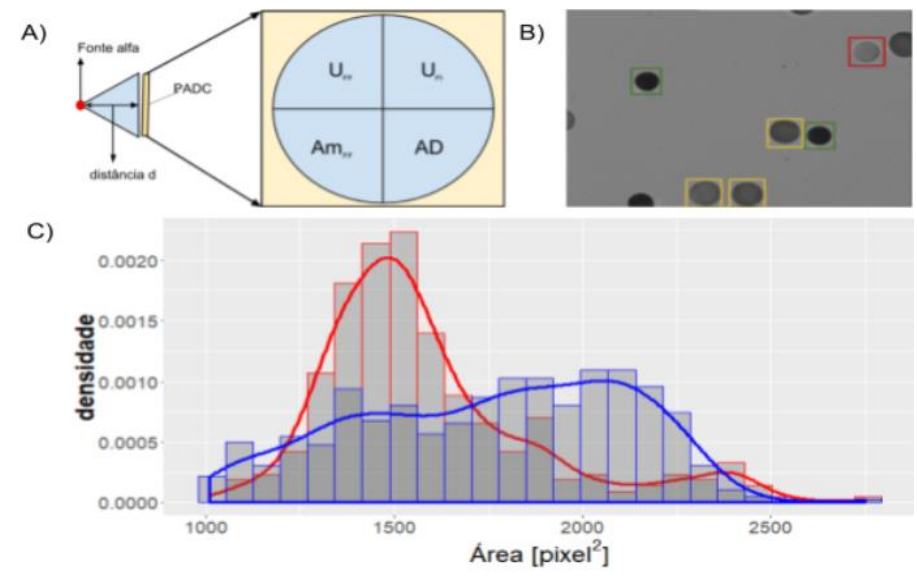

\section{Conclusões}

Com os resultados obtidos demos um passo importante para o desenvolvimento de um método que deverá permitir a separação entre $R n-222$ e seus filhos emissores alfa Po-214 e Po-218 no sentido de tornar a mais precisa a medida desta que é a maior contaminação a que o homem está sujeito.

\section{Agradecimentos}

Ao grupo de Cronologia do IFGW, à Unicamp e ao CNPQ pelo incentivo e investimento no trabalho.

Zuniga Gamarra, Agustin Ricardo. Caracterização do CR-39 como espectrômetro alfa. 1998. 151p. Tese (doutorado) - Universidade Estadual de Campinas, Instituto de Fisica "Gleb Wataghin", Campinas, SP. 